Supporting Information

\title{
Chemomechanical Design Factors for High-Performance in Manganese-Based Spinel Cathode Materials for Advanced Sodium-Ion Batteries
}

Hyungjun Kim, ${ }^{\dagger}$ Duho Kim, ${ }^{* \ddagger}$ and Maenghyo Cho*,†

${ }^{\dagger}$ Department of Mechanical and Aerospace Engineering, Seoul National University, Gwanakro 1, Gwanak-gu, Seoul 08826, Republic of Korea

${ }^{*}$ Department of Mechanical Engineering, Kyung Hee University, 1732, Deogyeong-daero, Giheung-gu, Yongin-si, Gyeonggi-do, 17104, Republic of Korea

*E-mail: duhokim@khu.ac.kr (Prof. D. Kim); mhcho@ snu.ac.kr (Prof. M. Cho). 

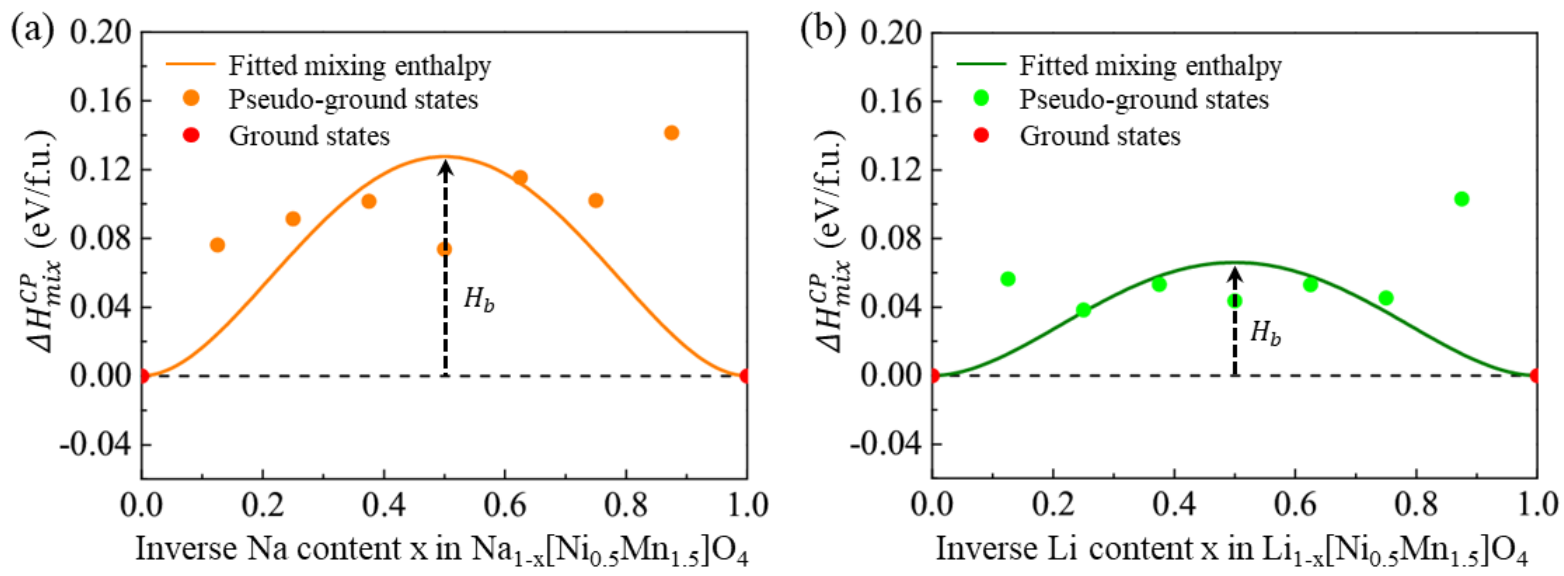

Figure S1. Combined-phase mixing enthalpy fitted from the ground/pseudo-ground states from first-principle formation energies of mixing enthalpy (a) in $\mathrm{Na}_{1-\mathrm{x}}\left[\mathrm{Ni}_{0.5} \mathrm{Mn}_{1.5}\right] \mathrm{O}_{4}$ and (b) in $\mathrm{Li}_{1-\mathrm{x}}\left[\mathrm{Ni}_{0.5} \mathrm{Mn}_{1.5}\right] \mathrm{O}_{4}$, from Figure $4 \mathrm{a}-\mathrm{b}$ using quadratic double-well function. 

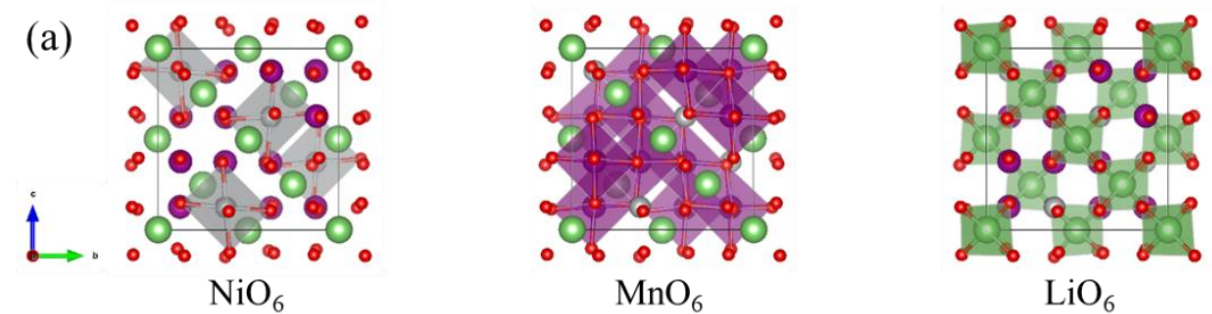

$\mathrm{Li}\left[\mathrm{Ni}_{0.5} \mathrm{Mn}_{1.5}\right] \mathrm{O}_{4}$

(b)

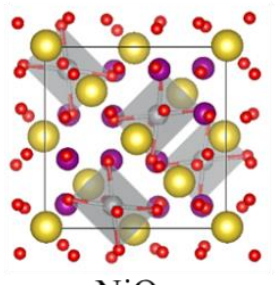

$\mathrm{NiO}_{6}$
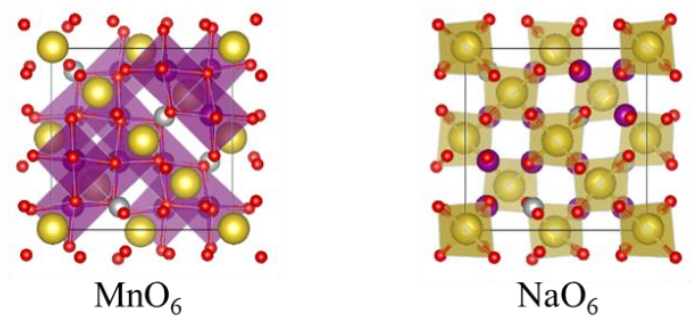

$\mathrm{Na}\left[\mathrm{Ni}_{0.5} \mathrm{Mn}_{1.5}\right] \mathrm{O}_{4}$

Figure S2. (a) $\mathrm{NiO}_{6}, \mathrm{MnO}_{6}$, and $\mathrm{LiO}_{6}$ octahedra in $\mathrm{Li}\left[\mathrm{Ni}_{0.5} \mathrm{Mn}_{1.5}\right] \mathrm{O}_{4}$. (b) $\mathrm{NiO}_{6}, \mathrm{MnO}_{6}$, and $\mathrm{NaO}_{6}$ octahedra in $\mathrm{Na}\left[\mathrm{Ni}_{0.5} \mathrm{Mn}_{1.5}\right] \mathrm{O}_{4}$. 


\begin{tabular}{ccccccccc}
\hline Material & $\begin{array}{c}\text { Guest ions } \\
\text { content }\end{array}$ & $\mathrm{c}_{11}[\mathrm{GPa}]$ & $\mathrm{c}_{12}[\mathrm{GPa}]$ & $\mathrm{c}_{44}[\mathrm{GPa}]$ & $\mathrm{B}_{\mathrm{H}}[\mathrm{GPa}]$ & $\mathrm{G}_{\mathrm{H}}[\mathrm{GPa}]$ & $\mathrm{E}_{\mathrm{H}}[\mathrm{GPa}]$ & $v_{\mathrm{H}}$ \\
\hline \multirow{2}{*}{ LNMO } & $\mathrm{x}=0$ & 178.09 & 82.71 & 78.20 & 114.50 & 64.13 & 162.13 & 0.26 \\
\cline { 2 - 9 } & $\mathrm{x}=1$ & 135.21 & 54.30 & 66.08 & 81.27 & 54.28 & 133.18 & 0.23 \\
\hline \multirow{2}{*}{ NNMO } & $\mathrm{x}=0$ & 143.03 & 95.12 & 59.04 & 111.09 & 41.12 & 109.81 & 0.34 \\
\cline { 2 - 9 } & $\mathrm{x}=1$ & 135.21 & 54.30 & 66.08 & 81.27 & 54.28 & 133.18 & 0.23 \\
\hline
\end{tabular}

Table S1. Components of constitutive tensor and the elastic properties of polycrystals in the Voight-Reuss-Hill approximation for $\mathrm{Li}_{1-\mathrm{x}}\left[\mathrm{Ni}_{0.5} \mathrm{Mn}_{1.5}\right] \mathrm{O}_{2}$ and $\mathrm{Na}_{1-\mathrm{x}}\left[\mathrm{Ni}_{0.5} \mathrm{Mn}_{1.5}\right] \mathrm{O}_{4}$. 


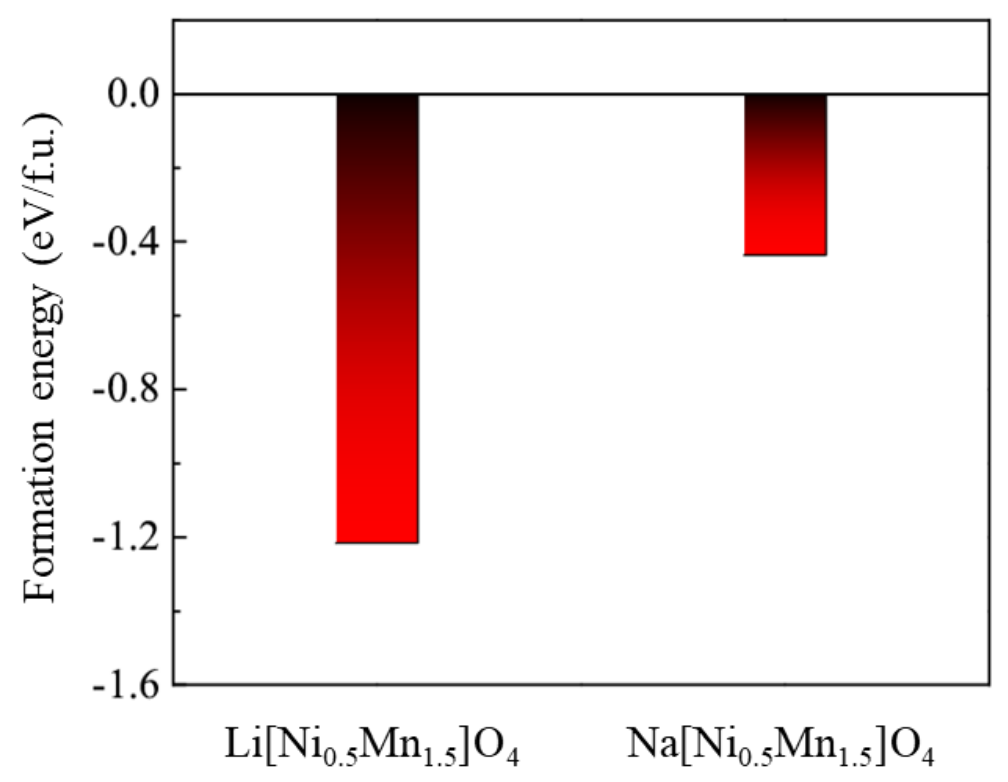

Figure S3. Formation energy per f.u. for $\mathrm{Li}\left[\mathrm{Ni}_{0.5} \mathrm{Mn}_{1.5}\right] \mathrm{O}_{4}$ and $\mathrm{Na}\left[\mathrm{Ni}_{0.5} \mathrm{Mn}_{1.5}\right] \mathrm{O}_{4}$. In the aspect of thermodynamic, material stability of $\mathrm{Li}\left[\mathrm{Ni}_{0.5} \mathrm{Mn}_{1.5}\right] \mathrm{O}_{4}$ and $\mathrm{Na}\left[\mathrm{Ni}_{0.5} \mathrm{Mn}_{1.5}\right] \mathrm{O}_{4}$ is determined based on the formation energy of transition metals ( $\mathrm{Ni}$ and $\mathrm{Mn}$ ) mixing. The equation for the formation energy for each material is defined as

$E_{\text {LNMO }}^{\text {Formation }}=E\left(\mathrm{Li}^{2}\left[\mathrm{Ni}_{0.5} \mathrm{Mn}_{1.5}\right] \mathrm{O}_{4}\right)-\frac{1}{4} E\left(\mathrm{LiNi}_{2} \mathrm{O}_{4}\right)-\frac{3}{4} E\left(\mathrm{LiMn}_{2} \mathrm{O}_{4}\right)$,
$E_{\text {NNMO }}^{\text {Formation }}=E\left(\mathrm{Na}\left[\mathrm{Ni}_{0.5} \mathrm{Mn}_{1.5}\right] \mathrm{O}_{4}\right)-\frac{1}{4} E\left(\mathrm{NaNi}_{2} \mathrm{O}_{4}\right)-\frac{3}{4} E\left(\mathrm{NaMn}_{2} \mathrm{O}_{4}\right)$.

Based on the formation energy equations, it is possible to determine whether the material is stable (negative value) or not (positive value). The formation energy for LNMO and NNMO is $\sim-1.2 \mathrm{eV} /$ f.u. and $\sim-0.4 \mathrm{eV} /$ f.u., respectively. It can be understood that the energy difference between LNMO and NNMO occurs because of the $\mathrm{Li}^{+}$and $\mathrm{Na}^{+}$sites occupying at the tetrahedral sites that are thermodynamically more stable for $\mathrm{Li}^{+}$than $\mathrm{Na}^{+}$. Although LNMO shows lower formation energy than NNMO, NNMO has negative formation energy resulting in a stable state, which indicates that both materials are thermodynamically stable. 
$\hat{t}=0.02$

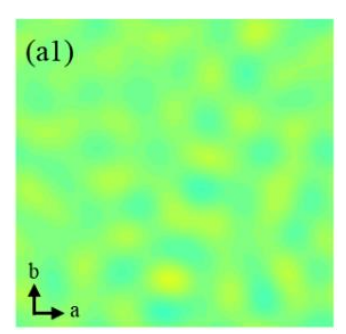

(b1)

$\stackrel{b}{\longrightarrow} a$ $\hat{t}=0.04$

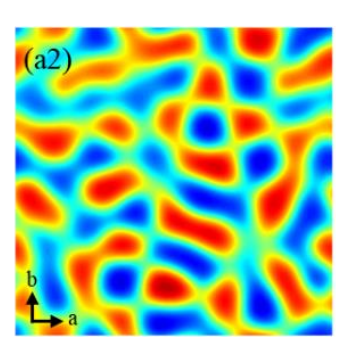

(b2)

$\stackrel{b}{\longrightarrow} \rightarrow a$ $\hat{t}=0.06$
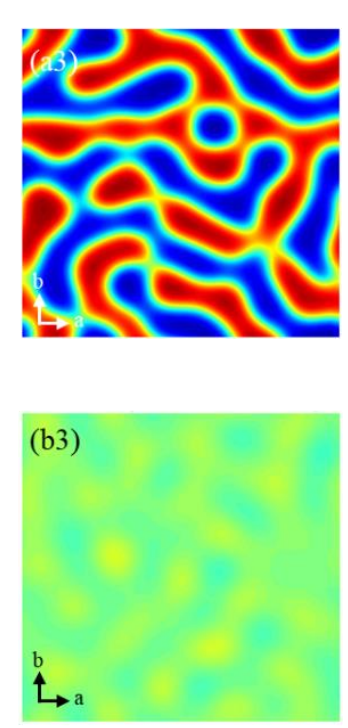

$\hat{t}=0.08$
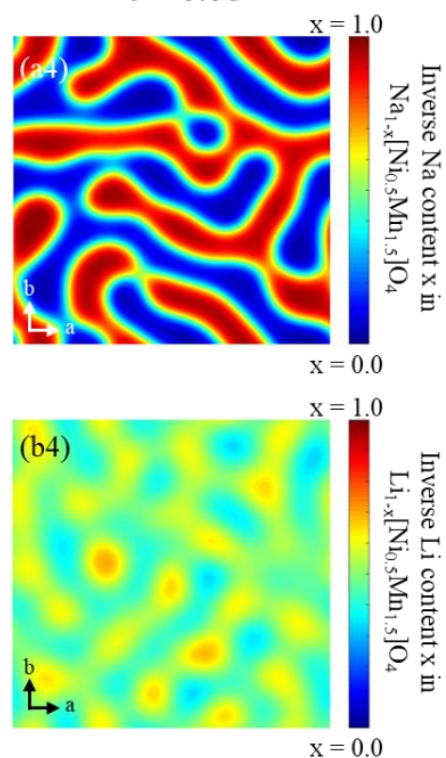

Figure S4. Contours of phase separation after (a1) $\hat{t}=0.02$, (a2) $\hat{t}=0.04$, (a3) $\hat{t}=0.06$, and (a4) $\hat{t}=0.08$ of $\mathrm{Na}\left[\mathrm{Ni}_{0.5} \mathrm{Mn}_{1.5}\right] \mathrm{O}_{4}$. Those for $\mathrm{Li}\left[\mathrm{Ni}_{0.5} \mathrm{Mn}_{1.5}\right] \mathrm{O}_{4}$ after (b1) $\hat{t}=0.02$, (b2) $\hat{t}=0.04$, (b3) $\hat{t}=0.06$, and (b4) $\hat{t}=0.08$, and all contours are on ab-plane. 

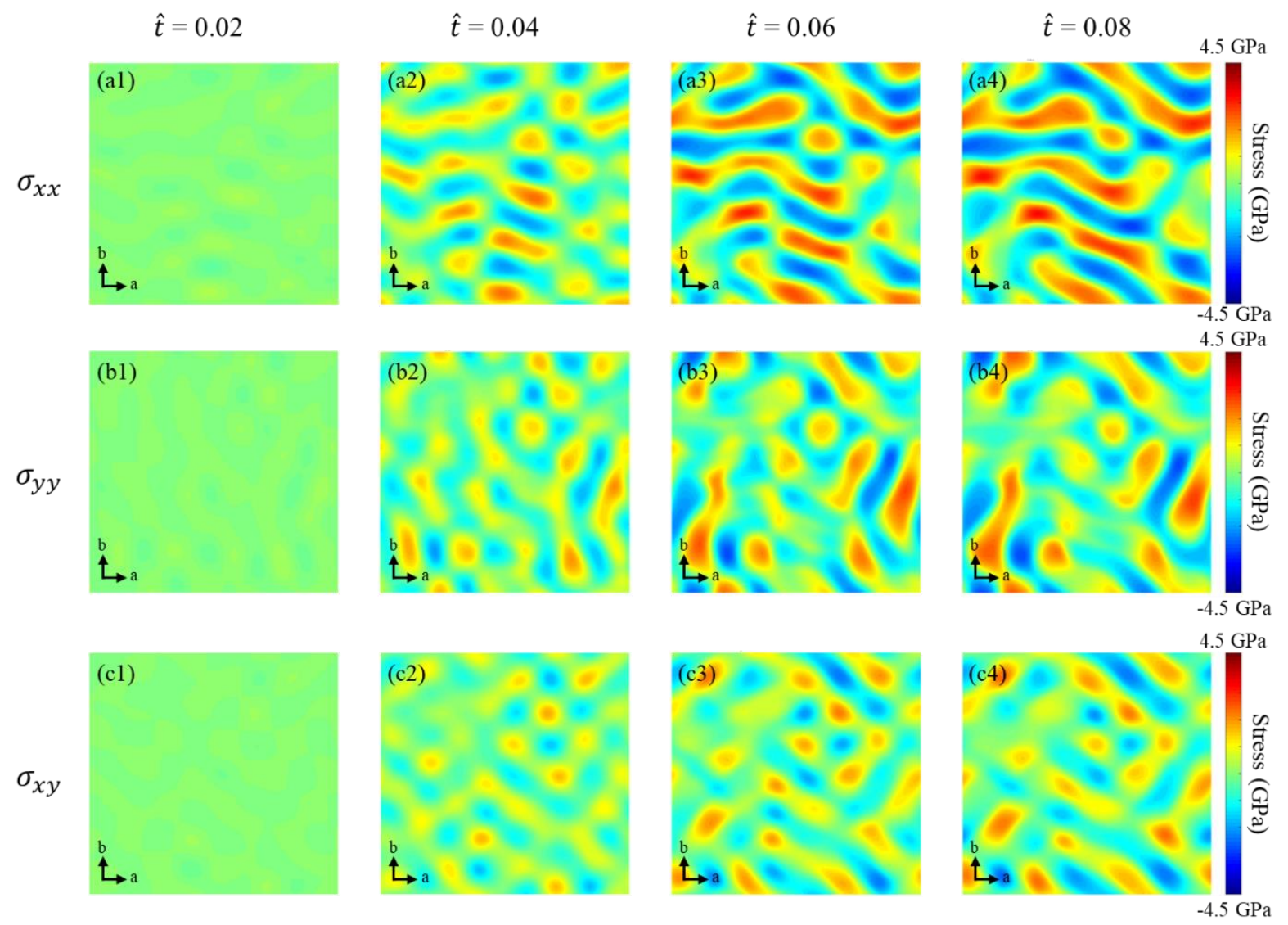

Figure S5. Stress fields in ab-plane, results of phase separation from $\hat{t}=0.02$ to $\hat{t}=0.08$, consisting of (a1-4) $\sigma_{x x},(\mathrm{~b} 1-4) \sigma_{y y}$, and (c1-4) $\sigma_{x y}$ for $\mathrm{Na}\left[\mathrm{Ni}_{0.5} \mathrm{Mn}_{1.5}\right] \mathrm{O}_{4}$. 

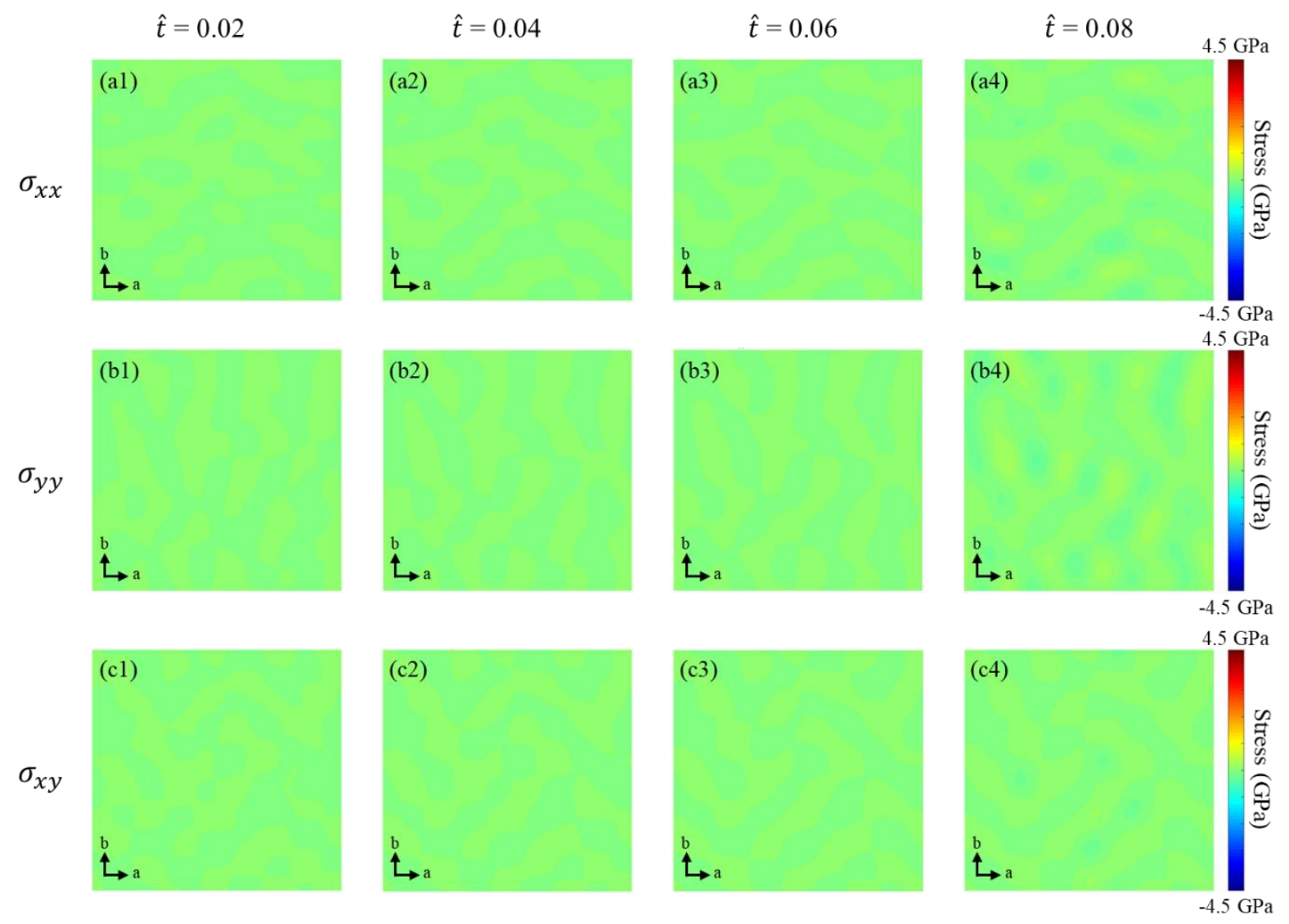

Figure S6. Stress fields in ab-plane, results of phase separation from $\hat{t}=0.02$ to $\hat{t}=0.08$, consisting of (a1-4) $\sigma_{x x},(\mathrm{~b} 1-4) \sigma_{y y}$, and (c1-4) $\sigma_{x y}$ for $\mathrm{Li}\left[\mathrm{Ni}_{0.5} \mathrm{Mn}_{1.5}\right] \mathrm{O}_{4}$. 